\title{
Radiopharmaceuticals for diagnosis in nuclear medicine: a short review
}

\author{
Filipe Boccato Payolla1 ${ }^{10}$, Antonio Carlos Massabni ${ }^{1,2+}{ }^{+\infty}$, Chris Orvig $3(0)$
}

1 University of Araraquara (Uniara), 1217 Carlos Gomes St., Araraquara, São Paulo, Brazil

2 São Paulo State University (Unesp), Institute of Chemistry, 55 Professor Francisco Degni St., Araraquara, São Paulo, Brazil

3 University of British Columbia (UBC), Faculty of Pharmaceutical Sciences, Department of Chemistry, Medicinal Inorganic Chemistry Group, 2405

Wesbrook Mall, Vancouver, British Columbia, Canada

+Corresponding author: Antonio Carlos Massabni, email address: amassabni@uol.com.br

\section{ARTICLE INFO}

Article history:

Received: January 30, 2019

Accepted: June 29, 2019

Published: July 4, 2019
Keywords:
1. radionuclide
2. nuclear medicine
3. diagnosis
4. radiopharmaceutical

ABSTRACT: Radiopharmaceuticals are radioactive compounds which have a bound radionuclide in their structure, whose purpose is directing the radionuclide to a location to be treated or to obtain images. Nuclear medicine is the medical specialty that employs radiopharmaceuticals, which has presented itself as a tremendously useful ally for medicine assisting in various diagnoses and treatments, especially for cancer. The general objective of this work is to identify the main radionuclides and metal complexes currently used as radiopharmaceuticals. The main metal complexes used as radiopharmaceuticals are compounds of technetium $\left({ }^{99 \mathrm{~m}} \mathrm{Tc}\right)$ like sodium pertechnetate and methylenediphosphonate MDP- ${ }^{99 \mathrm{~m}} \mathrm{Tc}$ and other compounds of indium $\left({ }^{111} \mathrm{In}\right)$, thallium $\left({ }^{201} \mathrm{Tl}\right)$, gallium $\left({ }^{67} \mathrm{Ga},{ }^{68} \mathrm{Ga}\right)$, iodine $\left({ }^{123} \mathrm{I}\right.$ and $\left.{ }^{131} \mathrm{I}\right)$, chromium $\left({ }^{51} \mathrm{Cr}\right)$, sulphur $\left({ }^{35} \mathrm{~S}\right)$, phosphorus $\left({ }^{32} \mathrm{P}\right)$, fluorine (as fluorodeoxyglucose, ${ }^{18} \mathrm{~F}-\mathrm{FDG}$ and sodium fluorine, $\mathrm{Na}^{18} \mathrm{~F}$ ), which are widely used in the nuclear medicine for diagnosis by imaging. They have been of great importance for the early diagnosis of numerous diseases, mainly cancer.Currently, technetium compounds are the majority of radiopharmaceuticals used in all countries. In Brazil, Institute of Energy and Nuclear Research (IPEN) is one of the most important distributors of radiopharmaceuticals, producing, importing and distributing them to clinics and hospitals over the country.

\section{CONTENTS}

\section{Introduction}

2. Historical Bases of Nuclear Medicine and Radioactivity

3. Nuclear Medicine and Radiopharmaceuticals

3.1 Nuclear medicine techniques

3.2. Radionuclides in medicine

3.3 Radiopharmaceuticals for diagnosis in human body

4. Production of radionuclides

5. Conclusions

\section{Acknowledgments \\ 7. References}

\section{Introduction}

In nuclear medicine, radiopharmaceuticals are used in diagnostic imaging and radiotherapy, being of utmost importance for medicine in general to assist in diagnoses of organs and treatments of pathological conditions, especially cancer. In the imaging modality, radiopharmaceuticals are administered via oral, intravenous, or by inhalation

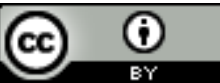


to enable visualization with their radioactive tracers of various organs, such as kidneys, lungs, thyroid and heart functions, bone metabolism and blood circulation. In therapeutic modality, aiming to treat cancer or over functioning thyroid gland, a high dose of radiation is delivered through specific radiopharmaceuticals targeting the diseased $\operatorname{organ}^{1}$.

Radiopharmaceuticals generally consist of two components, a radioactive element (radionuclide), that permits external scan, linked to a nonradioactive element, a biologically active molecule, drug or cell (red and white blood cells labeled with a radionuclide, for example) that acts as a carrier or ligand, responsible for conducting the radionuclide to a specific organ ${ }^{2}$.

Some characteristics are necessary for considering radiopharmaceuticals clinically useful for imaging: the decay of the radionuclide should be in specific ranges of energy emissions $(511 \mathrm{keV}$ for positron emission tomography - PET and 100$200 \mathrm{keV}$ for gamma cameras) and in sufficient quantity for tomography detection; 2) it should not contain particulate radiation (beta emissions, for example), because it increases the radiation dose in patients; 3) the half-life should be for a few hours only; 4) the radionuclides should not be contaminated by other radionuclides of the same element nor even its stable radionuclides (carrierfree); 5) they should have specific activity, and the highest specific activity comes from carrier-free radionuclides; 6) the radiopharmaceutical should not have toxicity and does not manifest physiological effects; 7) the radiopharmaceutical should be available for instant usage and easy to compound; 8) the radiopharmaceutical should reach the target organ quickly and accurately, according to its intended application ${ }^{3}$.

Diagnostic radiopharmaceuticals have no pharmacological effects and their administration is not associated with relevant clinical side effects. Its clinical use, however, carries the inherent risk of exposure to radiation and possible contamination during radiopharmaceutical formulation, since most radiopharmaceuticals are administered intravenously ${ }^{3}$.

The most notable difference between normal medicines and radiopharmaceuticals is that the former has therapeutic effect while the latter does not. Besides that, radiopharmaceuticals have a short half-life, because of their rapid decay. For this reason, radiopharmaceuticals must be prepared immediately before their administration. The preparation and use of radiopharmaceuticals with safety and expertise are therefore vital for operator and patient protection ${ }^{3}$.

Understanding the mechanism of interaction between the radioactive elements and the different molecules, drugs, cells and organs it is necessary for the development of more efficient imaging or therapeutic radiopharmaceuticals ${ }^{4}$.

\section{Historical Bases of Nuclear Medicine and Radioactivity}

Wilhelm Roentgen's work on X-ray studies has stimulated researchers such as Henri Poincaré whose studies are related to the hypothesis of X-ray emission and fluorescence. The first scientist to carry out the hypotheses proposed by Poincaré was Charles Henry, using zinc sulfide as an X-ray intensifier, concluding that in the presence of light, when the radiographs became sharper because of the substance ${ }^{5}$.

In 1896, Henri Becquerel used uranium salts on photographic plates, which resulted in marked radiographs without the presence of light. In 1905, Marie and Pierre Curie were the first to suggest radium for treatment of cancer. The Curies' work may be considered the beginning of modern nuclear medicine. In 1931, Ernest Lawrence built the first cyclotron, equipment that accelerated alpha particles, such as protons, deuterons, or helium ions, with the aim of penetrating the nucleus to produce stable and radioactive isotopes. A decade later, Lawrence's cyclotron had produced 223 radioactive isotopes, many of which are now of great value for medicinal uses and studies in the biological sciences ${ }^{6}$.

In 1930, Ernest Lawrence and Milton Livingstone, with their invention of the cyclotron, allowed the artificial production of new radioactive elements, but the quantities were very small. The medical use of radionuclides began during World War II with the Oak Ridge reactor in the United States, initiating the production of radionuclides in global scale. Hal Anger, in 1958, developed the image-scintillation chamber, which did not require the movement of the detector. It had a higher geometric resolution, and it was possible to obtain different projections of the same distribution of the radiopharmaceutical. However, computers were not yet capable of acquiring the information and transforming it into images. So, the information was sent to the cathode ray tube for it to be recorded on photographic plates or films. The modern 
scintillation cameras used nowadays are the Anger camera type ${ }^{7}$.

Nuclear Medicine only had a diagnostic power when Paul Harper and his group introduced the ${ }^{99 \mathrm{~m}} \mathrm{Tc}$ radionuclide as a marker. This radionuclide decays by isometric transition emitting photon with energy of $140 \mathrm{keV}$, gamma-type radiation and physical half-life of about 6 hours, which allows studies with reasonable intervals. In addition, it is obtained by the decay of the parent element ${ }^{99} \mathrm{Mo}$, produced in ${ }^{99} \mathrm{Mo} /{ }^{99 \mathrm{~m}} \mathrm{Tc}$ generators ${ }^{7}$.

The first radiopharmaceuticals were commercialized in $1950 .{ }^{131}$ Iodine was the first commercially available isotope, with Abbott Laboratories being the first company to produce radiopharmaceuticals for medical uses ${ }^{8}$.

The radioactive elements, thus classified, may have highly energetic unstable nuclides due to the excess of energy, which stabilizes by the emission of particles or electromagnetic radiation or charged particles during radioactive decay. In this context, there are three types of radiation: alpha, beta minus and gamma ${ }^{1,2}$. Radiation propagates at a certain speed and contains energy with electric and magnetic charges that can be generated by natural sources or by artificial devices, such as a cyclotron. Ionizing radiation is generated from the energy emitted by an unstable nucleus in artificial form or by a cyclotron ${ }^{5}$.

\section{Nuclear Medicine and Radiopharmaceuticals}

Radiopharmaceuticals may be divided in two distinct groups: one that includes radionuclides with radioactive decay period (half life) less than 2 $\mathrm{h}$, and other that includes radionuclides with half life higher than $2 \mathrm{~h}^{9}$.

Nuclear medicine cameras are proper for identifying radioactive particles. The type of radiation emitted defines the type of camera: SPECT cameras are used to detect nuclides that decay through direct emission of single gamma rays, and PET cameras are able to detect the pair of gamma rays emitted after a decay of positron ${ }^{10}$.

\subsection{Nuclear medicine techniques}

Diagnostic techniques in nuclear medicine use radioactive tracers that emit gamma radiation from within the body. The camera constructs an image from the points where the radiation is emitted. This image is magnified on a computer and it can be observed on a monitor that indicates the anomalies ${ }^{11}$.

The nuclear medicine techniques include Single Photon Emission Computerized Tomography (SPECT), Positron Emission Tomography (PET), and computed tomography-PET (PET-CT) (for better anatomical visualization), micro-PET (with ultra-high resolution) and microcomputerized axial tomography micro-CAT. These techniques are used to analyze biochemical dysfunctions as early signs of the disease, its mechanisms and association with disease states from cancer to cardiovascular diseases and mental disorders ${ }^{6,12}$.

A SPECT exam is used primarily to visualize the blood flow through veins and arteries, and to perform pre-surgical evaluation of seizures. SPECT is also useful in the diagnosis of blood deprived areas of brain (ischemic), spinal stress fractures (spondylolysis) and tumors ${ }^{10}$.

The PET imaging detects the pair of gamma rays produced by the interaction between a positron and an electron in the tissues of the body. The electron and the positron neutralize each other producing two gamma rays in opposite directions. PET detects the electronic signal converting with scintillation crystals the energy released by gamma rays ${ }^{10}$.

${ }^{99 \mathrm{~m}}$ Technetium is the radionuclide that has the best characteristics to combine with gamma cameras and ${ }^{18}$ fluorine has the most desirable characteristics for PET $^{3}$.

Although the SPECT and PET techniques capture images with high intensity, they have low spatial resolution because they are directed to the surface of the body they are accurately visualized. On the other hand, computerized tomography (CT) and magnetic resonance have greater spatial resolution, but with less sensitivity. To obtain such restrictions, the techniques are merged for images with excellent spatial resolution combined with high sensitivity ${ }^{10}$.

$\mathrm{X}$-ray $\mathrm{CT}$ has a computational process that makes a three-dimensional image, resulting in images with much greater resolution and quantity of details of internal structures and organs of the body ${ }^{6}$. There are other non-nuclear techniques, which are not described in this review, but could be accessed in this reference ${ }^{10}$.

\subsection{Radionuclides in medicine}

Radionuclides have many applications in several areas that use nuclear technology. The use 
of radiation and radionuclides in medicine is continuously increasing both for diagnosis and therapy worldwide.

In developed countries ( $1 / 4$ of the world's population), one person in 50 is subject to nuclear medicine and the frequency of radionuclide therapy is about $10 \%$ of that number, according to the World Nuclear Association ${ }^{11}$.

Radiation is used in nuclear medicine to obtain information about the organs of a person for treatment of a disease. In many cases, information is used for a quick diagnosis. Thyroid, bones, heart, liver, kidney and many other organs can be easily observed in the generated image and the anomalies of its functions are revealed. About 10,000 hospitals worldwide use radionuclides and about $90 \%$ of the procedures are for diagnosis. The radionuclide most used in diagnostics is ${ }^{99 \mathrm{~m}} \mathrm{Tc}$. It has been used in about 40 million exams per year, which means $80 \%$ of all exams in nuclear medicine worldwide ${ }^{11}$.

Radionuclides are essential components of diagnostic exams. In combination with the equipment recording the images from the emitted gamma rays, the processes that occur in various parts of the body can be studied. For diagnosis, a dose of the radioactive material is given to the patient and the localization in the organ can be studied as a two-dimensional image or, using tomography, as a three-dimensional image. These gamma or positron tracers have short-lived isotopes and are linked to chemical compounds that allow specific physiological processes to be evaluated ${ }^{10,11}$

In the USA, more than 20 million medical applications per year are performed using radionuclides and in Europe about 10 million per year $^{11}$. In Brazil, the Nuclear and Energy Research Institute (IPEN) reported that, in 2017, there were 360 diagnostic clinics and nuclear medicine hospitals, $70 \%$ in the South and Southeast regions of Brazil, 72 PETs installed, others to be licensed, 33 hospitals with rooms for therapy and approximately 1.8 million patients per year ${ }^{14}$.

\subsection{Radiopharmaceuticals for diagnosis in human body}

Medical doctors and chemists have identified a large number of chemicals that are absorbed by specific organs. Thyroid, for example, absorbs iodine while the brain absorbs glucose. Diagnostic radiopharmaceuticals can be used to monitor blood flow to the brain, liver, lung, heart, and kidney ${ }^{14}$.

Particulate radiation can be useful for destroying or weakening cancer cells (radiotherapy). The radionuclide that generates the radiation can be located in a certain organ in the same way used for diagnostics. In many cases, beta radiation causes the destruction of cancer cells. ${ }^{177}$ Lutetium $\left({ }^{177} \mathrm{Lu}\right)$, for example, is prepared from ${ }^{176}$ ytterbium $\left({ }^{176} \mathrm{Yb}\right)$ which is irradiated to transform it into ${ }^{177} \mathrm{Yb}$, which rapidly returns to ${ }^{177} \mathrm{Lu} .{ }^{90} \mathrm{Yttrium}\left({ }^{90} \mathrm{Y}\right)$ is used to treat cancer, especially non-Hodgkin's lymphoma and liver cancer. ${ }^{131}$ Iodine $\left({ }^{131} \mathrm{I}\right),{ }^{153}$ samarium $\left({ }^{153} \mathrm{Sm}\right)$ and ${ }^{32}$ phosphorus $\left({ }^{32} \mathrm{P}\right)$ are also used in radiotherapy. ${ }^{131} \mathrm{Cesium} \quad\left({ }^{131} \mathrm{Cs}\right),{ }^{103}$ palladium $\left({ }^{103} \mathrm{Pd}\right)$ and ${ }^{223}$ radium $\left({ }^{223} \mathrm{Ra}\right)$ are used in special cases ${ }^{11}$.

Figure 1 lists the radionuclides most commonly used for diagnosis and treatment of different organs of the human body. 


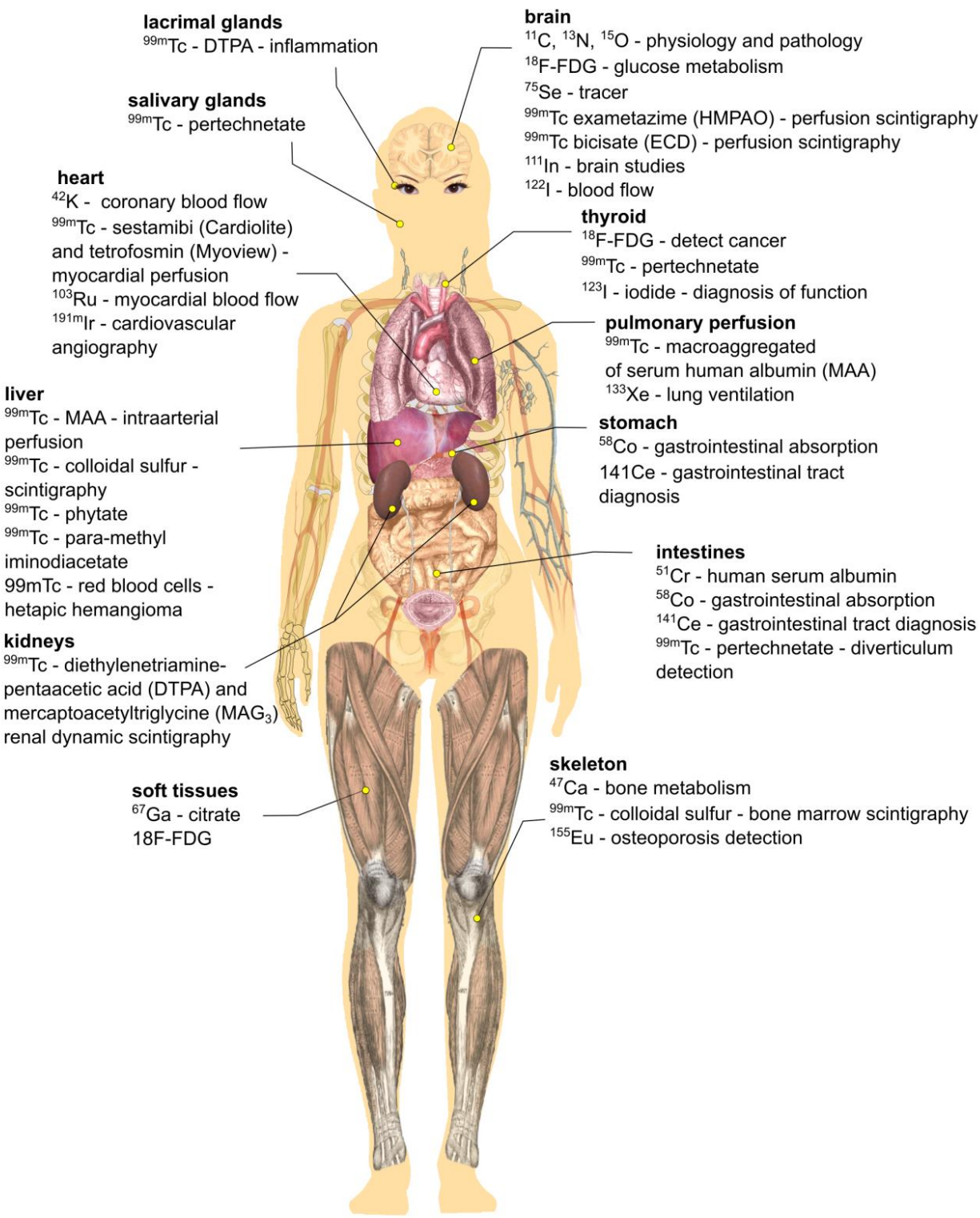

Figure 1. Different radiopharmaceuticals and target organs for imaging ${ }^{4,13,14}$. Image released into the public domain, changed for the review purposes ${ }^{15}$.

\section{Production of radionuclides}

Radionuclides found in nature, such as uranium and radium, are heavy elements with high toxicity and long half-life (over 1,000 years), so they are not used clinically. Radionuclides used in nuclear medicine are artificially produced by neutron bombardment or nuclear fission ${ }^{4}$.

Many radionuclides are produced in nuclear reactors and cyclotrons. Generally, neutron-rich radioisotopes and those resulting from nuclear fission are produced in reactors (Table 1) and the neutron-poor radioisotopes are produced in cyclotrons (Table 2). There are about 30 radioisotopes produced by activation and 5 are reactor melt products. A list with 70 elements, their isotopes, half-lives, decay, main energy and applications can be found in the reference ${ }^{14}$. 
Table 1. 30 selected radionuclides produced by nuclear fission ${ }^{14}$.

\begin{tabular}{|l|l|l|}
\hline${ }^{213}$ bismuth & ${ }^{59}$ iron & ${ }^{153}$ samarium \\
\hline${ }^{131}$ caesium & ${ }^{212}$ lead & ${ }^{75}$ selenium \\
\hline${ }^{137}$ caesium & ${ }^{177}$ lutetium & ${ }^{24}$ sodium \\
\hline${ }^{51}$ chromium & ${ }^{99}$ molybdenum & ${ }^{89}$ strontium \\
\hline${ }^{60}$ cobalt-60 & ${ }^{103}$ palladium & ${ }^{99}$ technetium \\
\hline${ }^{165}$ dysprosium & ${ }^{32}$ phosphorus & ${ }^{227}$ thorium \\
\hline${ }^{169}$ erbium & ${ }^{42}$ potassium & ${ }^{133}$ xenon \\
\hline${ }^{166}$ holmium & ${ }^{223}$ radium & ${ }^{169}$ ytterbium \\
\hline${ }^{131}$ iodine & ${ }^{186}$ rhenium & ${ }^{177}$ ytterbium \\
\hline
\end{tabular}

Table 2. 18 selected radionuclides produced by cyclotrons ${ }^{14}$.

\begin{tabular}{|l|l|}
\hline${ }^{225}$ actinium & ${ }^{67}$ copper \\
\hline${ }^{211}$ astatine & ${ }^{67}$ gallium \\
\hline${ }^{213}$ bismuth & ${ }^{127}$ xenon \\
\hline${ }^{11}$ carbon & ${ }^{111}$ indium \\
\hline${ }^{13}$ nitrogen & ${ }^{123}$ iodine \\
\hline${ }^{15}$ oxygen & ${ }^{124}$ iodine \\
\hline${ }^{18}$ fluorine & ${ }^{81 m}$ krypton \\
\hline${ }^{57}$ cobalt & ${ }^{82}$ rubidium \\
\hline${ }^{64}$ copper & ${ }^{201}$ thallium \\
\hline
\end{tabular}

In Brazil, the main producer of radiopharmaceuticals is IPEN, located in the city of São Paulo, state of São Paulo. IPEN is the only producer in the country of the ${ }^{99 \mathrm{~m}}$ technetium generator, which is used in $80 \%$ of the nuclear medicine procedures in Brazil. IPEN is also responsible for the production of 38 radiopharmaceuticals with distribution for all the Brazilian states ${ }^{13}$. According to data from the National Commission for Nuclear Energy (CNEN) Management Report for 2017, published in August 2018, about the radiopharmaceutical industry in Brazil, the main producers of radiopharmaceuticals are: Nuclear and Energy Research Institute (IPEN - São Paulo), Nuclear Technology Development Center (CDTN - Belo Horizonte), Northeast Regional Center for Nuclear Sciences (CRCN-NE - Recife), Nuclear Engineering Institute (IEN - Rio de Janeiro) operating nuclear reactors and particle accelerators, producing and commercializing supplies for the medical area. The Institute of Radiation Protection and Dosimetry (IRD - Rio de Janeiro) and the Laboratory of Poços de Caldas
(LAPOC - Poços de Caldas) are research laboratories that provide services to other laboratories, industries and companies and do not produce radiopharmaceuticals ${ }^{13}$.

The constitutional amendment 49 published in February 9, 2006 defines that production, commercialization and use of radionuclides with a half-life less than or equal to two hours are authorized and commercialization and use of radionuclides for research and medical, agricultural and industrial uses ${ }^{14}$.

Table 3 shows the radiopharmaceuticals produced in Brazil and places where they are manufactured.

Table 3. Radiopharmaceuticals produced in Brazil $^{13}$.

\begin{tabular}{|c|c|}
\hline Product & $\begin{array}{c}\text { Place of } \\
\text { production }\end{array}$ \\
\hline sodium iodide $\left({ }^{123} \mathrm{I}\right)$ & IEN \\
\hline sodium iodide $\left({ }^{131} \mathrm{I}\right)$ & IPEN \\
\hline gallium citrate $\left({ }^{67} \mathrm{Ga}\right)$ & IPEN \\
\hline thallium chloride $\left({ }^{201} \mathrm{Tl}\right)$ & IPEN \\
\hline sodium chromate $\left({ }^{51} \mathrm{Cr}\right)$ & IPEN \\
\hline generator ${ }^{99} \mathrm{Mo}-{ }^{99 \mathrm{~m}} \mathrm{Tc}$ & IPEN \\
\hline sodium sulfate $\left({ }^{35} \mathrm{~S}\right)$ & IPEN \\
\hline phosphoric acid $\left({ }^{32} \mathrm{P}\right)$ & IPEN \\
\hline sodium phosphate $\left({ }^{32} \mathrm{P}\right)$ & IPEN \\
\hline${ }^{18}$ fluorodeoxyglucose \\
$\left({ }^{18} \mathrm{~F}-\mathrm{FDG}\right)$ & IPEN, IEN, \\
& $\mathrm{CDTN}$, \\
\hline EDTMP $\left({ }^{153} \mathrm{Sm}\right)$ & CRCN-NE \\
\hline sodium fluoride $\left(\mathrm{Na}{ }^{18} \mathrm{~F}\right)$ & IPEN, CDTN \\
\hline${ }^{111}$ indium $\left({ }^{111} \mathrm{In}\right)$ & IPEN \\
\hline dotatate $\left({ }^{177} \mathrm{Lu}\right)$ & IPEN \\
\hline
\end{tabular}

In addition to these radiopharmaceuticals, CNEN supplies sealed sources $\left({ }^{133} \mathrm{Ba},{ }^{137} \mathrm{Cs}\right.$ and $\left.{ }^{57} \mathrm{Co}\right),{ }^{192} \mathrm{Ir}$ and ${ }^{125} \mathrm{I}$ seeds, both used in oncological treatments, using brachytherapy procedures ${ }^{13}$.

Production of technetium in Brazil still depends on raw material from foreign origin $\left({ }^{99}\right.$ molybdenum), and on the costs of importation. However, within the next few years, the CNEN aims at implementing the Brazilian Multipurpose Reactor (RMB) in the city of Iperó, state of São Paulo. Also, the Federal Government plans to initiate RMB's usage in 2024, becoming independent and guaranteeing the nationalization of the ${ }^{99}$ molybdenum radionuclide for the country's 
demand $^{16,17}$. This reactor must produce circa 1,000 $\mathrm{Ci}$ of ${ }^{99} \mathrm{Mo}$ per week (Ci (curie) is a unit of radionuclide activity, defined as: $1 \mathrm{Ci}=3,7 \times 10^{10}$ disintegrations per second ${ }^{20}$ ). As a comparison, in 2014, national demand was $450 \mathrm{Ci}{ }^{99} \mathrm{Mo} /$ week $^{17,18}$; the worldwide demand, in 2018, was $9400 \mathrm{Ci}$ ${ }^{99} \mathrm{Mo} /$ week ${ }^{19}$.

Figure 2 shows all cyclotrons installed and in operation in Brazil in 2019.

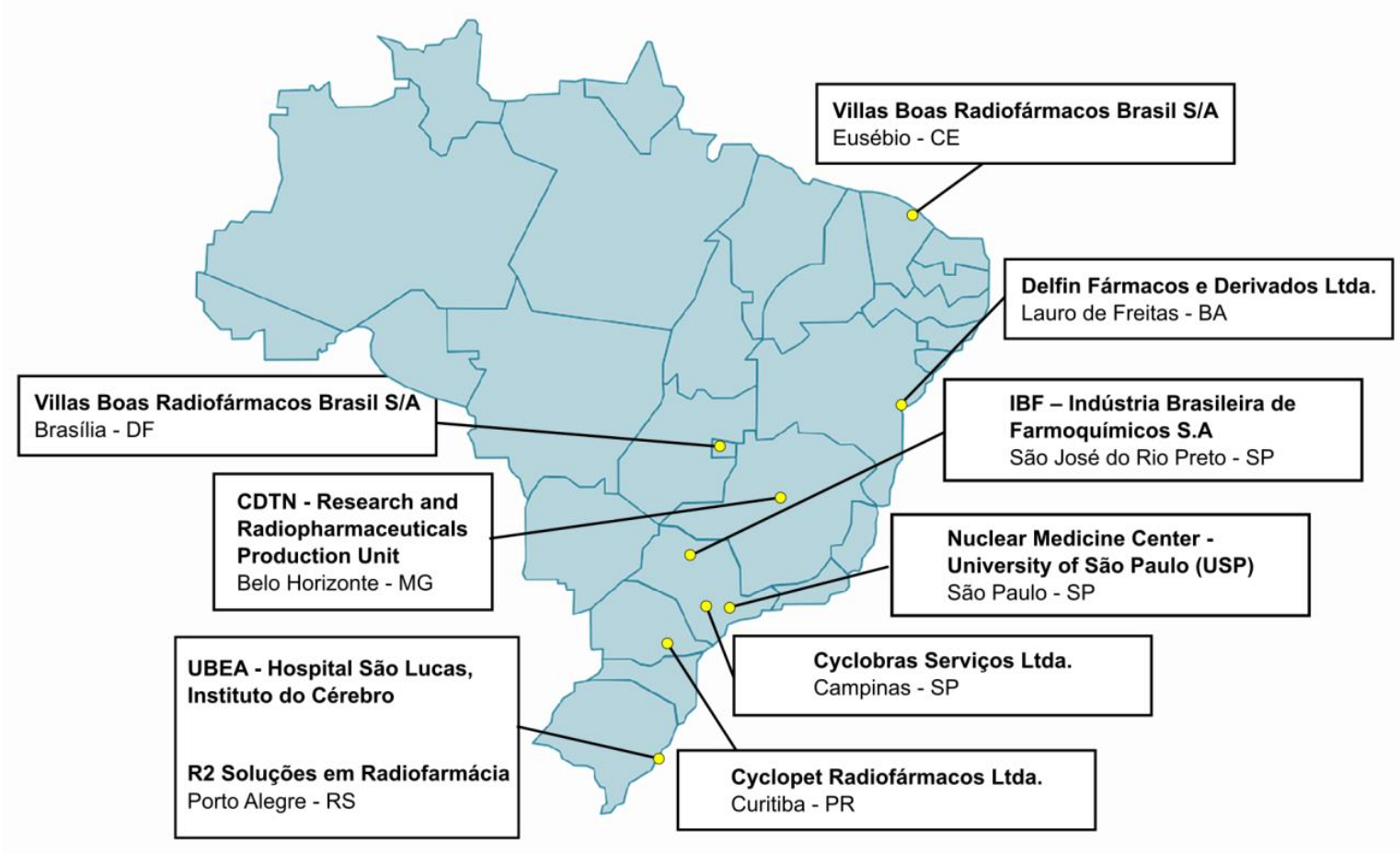

Figure 2. Cyclotron installations in $\mathrm{Brazil}^{21}$. Image released into the public domain, changed for the review purposes ${ }^{22}$.

The main difficulties for production of new radiopharmaceuticals in Brazil are the lack of a $70 \mathrm{MeV}$ high energy cyclotron accelerator in the country and the adequacy of the facilities to follow the Brazilian National Sanitary Surveillance Agency (Anvisa) Resolution n ${ }^{\circ} 63^{14}$.

\section{Conclusions}

Radionuclides have many applications in several areas which use nuclear energy. The importance and uses of radionuclides in medicine is continuously increasing for diagnosis and therapy worldwide. In 2018, about 10,000 hospitals used radionuclides and about $90 \%$ of the procedures were for diagnosis. In Brazil, the Institute of Energy and Nuclear Research (IPEN) reported that in 2017 there were more than 440 diagnostic clinics and nuclear medicine hospitals, $55 \%$ in the Southeast region of Brazil, $19 \%$ in Northeast and $15 \%$ in South region; 72 PETs installed, with about 1.8 million people supported.
There are about 40 radionuclides produced in nuclear reactors and about 20 radionuclides produced in cyclotrons.

${ }^{99 \mathrm{~m}}$ Technetium is the most used radionuclide for diagnosis, accounting for $67.3 \%$ of total CNEN revenue in 2017. Besides ${ }^{99 \mathrm{~m}} \mathrm{Tc},{ }^{131} \mathrm{I}(13.7 \%),{ }^{67} \mathrm{Ga}$ $(2.9 \%),{ }^{177} \mathrm{Lu}$ Dotatate $(2.9 \%)$ and ${ }^{18}$ F-FDG $(1.1 \%)$ were more frequently used in Brazil in 2017.

SPECT and PET are the two most used techniques in nuclear medicine during a large period, but nowadays other techniques with more accurate results are emerging, among them X-ray computed tomography $\mathrm{e}$ with three-dimension images.

\section{Acknowledgements}

The authors thank the support from São Paulo Research Foundation (FAPESP Proc. $\mathrm{n}^{\circ}$ 2017/11570-3). 


\section{References}

[1] World Health Organization (WHO). Diagnostic imaging. Nuclear Medicine. https://www.who.int/diagnostic_imaging/imaging_mod alities/dim_nuclearmed/en/.

[2] Cherry, S. R., Sorenson, J. A., Phelps, M. E. Physics in Nuclear Medicine. Elsevier Inc. ISBN 978-1-41605198-5

2012.

https://www.sciencedirect.com/topics/neuroscience/rad iopharmaceuticals.

[3] International Atomic Energy Agency (IAEA). Operational guidance on hospital radiopharmacy : a safe and effective approach. Vienna: International Atomic Energy Agency, 2008. ISBN 978-92-0-106708-1. https://www-

pub.iaea.org/MTCD/publications/PDF/Pub1342/Pub13 42_web.pdf.

[4] Ziessman, H. A., O’Malley, J. P., Thrall, J. H. (eds.). Radiopharmaceuticals, In: Nuclear Medicine, $4^{\text {th }}$ ed., W. B. Saunders: Philadelphia, USA, 2014, ch. 1. ISBN 9780323082990. https://doi.org/10.1016/B978-0-32308299-0.00001-8.

[5] Malley, M. C., Radioactivity: a history of a mysterious science, Oxford University Press, New York, 2011, ISBN 978-0-19-976641-31.

[6] L'Annunziata, M. F., Radioactivity: introduction and history, from the quantum to quarks, Elsevier, $2^{\text {nd }}$ ed., 2016. eBook ISBN: 9780444634962.

[7] Robilotta, C. C., A tomografia por emissão de pósitrons: uma nova modalidade na medicina nuclear brasileira, Rev. Panam. Salud Pública 20 (2/3) (2006) 134-42. https://doi.org/10.1590/S1020-

49892006000800010.

[8] Santos-Oliveira, R., Carneiro-Leão, A. M. A., A história da radiofarmácia e as implicações da Emenda Constitucional $n^{\circ}$ 49. Rev. Bras. Cienc. Farm. 44 (3) 2008.

http://qnesc.sbq.org.br/online/cadernos/06/a08.pdf.

[9] Comissão Nacional de Energia Nuclear (CNEN), RMB e a Produção de Radiofármacos. http://www.cnen.gov.br/radiofarmacos.

[10] Wells, R. G., Instrumentation in molecular imaging. J. Nucl. Cardiol. 23 (6) 2016, 1343-1347. https://doi.org/10.1007/s12350-016-0498-z.

[11] World Nuclear Association (WNA). Radionuclides in medicine. (Updated November 2018). http://www.world-nuclear.org/information-library/nonpower-nuclear-applications/radionuclidesresearch/radionuclides-in-medicine.aspx.

[12] K, Seyed. Molecular Nuclear Imaging: The Radiopharmaceuticals (Review) .Cancer Biotherapy and $\begin{array}{lll}\text { Radiopharmaceuticals, } & 20 & \text { (2) } 2005 .\end{array}$ https://doi.org/10.1089/cbr.2005.20.163.

[13] Comissão Nacional de Energia Nuclear (CNEN), Ministério da Ciência, Tecnologia, Inovação e Comunicações, Relatório de Gestão do exercício de 2017.

http://www.cnen.gov.br/images/cnen/documentos/acess o_a_informacao/Rel-gestao-2017.pdf.

[14] European Organization for Nuclear Research (CERN), A table of frequently used radioisotopes CERN Document Server. C. Grupen, Introduction to Radiation Protection, Graduate Texts in Physics, 2010. https://doi.org/10.1007/978-3-642-02586-0.

[15] Wikimedia Commons, the free media repository, 'File: Female shadow template.svg'. https://commons. wikimedia.org/w/index.php?title=File :Female_shadow_template.svg\&oldid=302058264.

[16] Amazônia Azul Tecnologias de Defesa S.A. (Amazul), Reator Multipropósito Brasileiro. https://www.marinha.mil.br/amazul/acesso-ainformacao/acoes-e-programas/programas/reatormultiproposito-brasileiro.

[17] Instituto de Pesquisas Energéticas e Nucleares (IPEN). Brazilian Multipurpose Reactor - Progress Report. 6 p. 2016. https:/www.ipen.br/portal_por/conteudo/documentos/ PR_2014_2016_13_Brazilian_Multipurpose_Reactor.p df.

[18] Pozzo, L., Coura Filho, G., Osso Júnior, J. A., Squair, P. L., SUS in nuclear medicine in Brazil: analysis and comparison of data provided by Datasus and CNEN, Radiol. Bras., 47 (3) (2014) 141-148. https://doi.org/10.1590/0100-3984.2013.1906.

[19] Nuclear Energy Agency (NEA), Steering Committee For Nuclear Energy, High-Level Group on the Security of Supply of Medical Radioisotopes, The supply of medical radioisotopes - 2018 medical isotope demand and capacity projection for the 2018-2023 period.

http://www.oecd.org/officialdocuments/publicdisplayd ocumentpdf/?cote=NEA/SEN/HLGMR(2018)3\&docLa nguage $=$ En .

[20] International Atomic Energy Agency (IAEA). Activity measurement principles. 
https://humanhealth.iaea.org/HHW/MedicalPhysics/Nu clearMedicine/ActivityMeasurements/ActMeasPrincipl es/index.html

[21] Comissão Nacional de Energia Nuclear (CNEN), Instalações Autorizadas. Produção de Radioisótopos (Cíclotron) - Posição em 02/06/2019. http://appasp.cnen.gov.br/seguranca/cons-ent-prof/lstentidades-aut-cert.asp?p_ent=22\&d=Produção de Radioisótopos (Ciclotron).

[22] Pixabay. 'File: brazil-23553_960_720.png'. Pixabay, 2 Apr. 2012. Available from: https://pixabay.com/pt/vectors/brasil-mapa-américa-dosul-estados-23553/. 